\title{
How effective is aeration with vortex flow regulators? Pilot scale experiments
}

\author{
Patryk Wójtowicz ${ }^{1, *}$, and Małgorzata Szlachta \\ ${ }^{1}$ Wrocław University of Science and Technology, Faculty of Environmental Engineering, Wybrzeże \\ Wyspiańskiego 27, 50-350 Wrocław, Poland
}

\begin{abstract}
Vortex flow regulators (VFR) are used in urban drainage systems as a replacement for traditional flow throttling devices. Vortex regulators are not only very efficient energy dissipators but also atomizers which are beneficial for sewer aeration. A deficit of dissolved oxygen can be a problem in both natural waters and sewerage. Hydrodynamic flow regulators can boost oxygen concentration preventing putrefaction and improving treatment of stormwater and wastewater. We were first to investigate the aeration efficiency of semi-commercial scale cylindrical vortex flow regulators to determine the potential of their application in environmental engineering and to propose modification to enhance the aeration capacity of basic designs. Different device geometries and arrangements of active outlets for both single and double discharge vortex regulators were tested in a recirculating system. In this study, we present a concise review of the current state of our extensive research on the aeration efficiency of vortex flow regulators and their application in sewerage systems.
\end{abstract}

\section{Introduction}

Vortex flow regulators (VFR) (known as hydrodynamic flow regulators) are used in urban drainage systems as a replacement for traditional flow throttling devices. Vortex regulators are very versatile and can be used in gravitational as well as pressurised systems with different configurations. Their application is not limited to storm or wastewater systems. They can be used in other fields too, e.g. in water distribution - for water hammer protection or in hydraulic structures - for limiting outflow from a dam [1].

From a practical point of view, vortex regulators are compact, efficient in throttling, reliable and free from common disadvantages of the traditional regulation devices. To throttle the flow efficiently, they do not need to reduce the pipe cross-section, do not require power supply or moving parts. Vortex devices are fascinating with their simple design and straightforward operational principle, as opposed to a highly complex vortex motion employed, which defies a complete solution for over 100 years now [2-5].

Our research indicated that the atomisation of a liquid by vortex flow regulators accelerates oxygenation and prevents the putrefaction process in wastewater and storm water collection systems [6]. This feature is a positive side effect - intrinsic to the

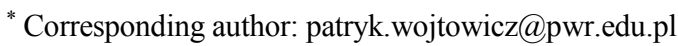


operational principle. A deficit of dissolved oxygen is a known problem in both natural waters and sewerage systems [7,8]. Therefore, there is an important need to utilise effective and inexpensive methods and devices to restore the oxygen balance [9].

To date, there has been no systematic research available in the literature regarding the aeration efficiency of vortex flow regulators and this was a main motivation for this long-term study. We were first to investigate the aeration efficiency of semi-commercial scale cylindrical vortex flow regulators to determine their application potential in environmental engineering and propose modification to enhance the aeration capacity of basic designs. To obtain research goals both experimental and computational methods were used at laboratory and semi-commercial scale [10]. A wide range of device geometries and arrangements of active outlets for both single and double discharge vortex regulators (patented) were tested. The main assumption was that modifications should not compromise any of the advantages and especially simple structure, reliability and extreme throttling efficiency.

In this paper, we aim to present the current state-of-the-art cylindrical vortex regulator (CVR) designs and a concise summary of several years of research on aeration efficiency of vortex flow regulators.

\section{Materials and methods}

Semi-commercial scale models of hydrodynamic flow regulators were tested in a recirculating hydraulic system. The experimental setup consisted of a feed tank equipped with a circulation pump, an upper tank and a supply system where the models were tested. The flow rate and pressure drop were continuously recorded while the air core diameter and spray cone angle were determined based on photographs.

Different device geometries and arrangements of active outlets for both single and double discharge vortex regulators were tested. The experimental programme included tests of three types of vortex regulators shown in Figure 1a-c. The first type (CVR - Fig. 1a) is well-known, basic designs originally developed to maximise throttling performance. They discharge only through the bottom outlet. Using the CVR type as a baseline, we proposed two new types with enhanced aeration capability (both have been patented). The first modification was the addition of a second outlet in the top plate (CVR-2 - Fig. 1b). In the next modification (CVR-U - Fig. 1c), only the top outlet is used, although the bottom outlet was open and used to drain the device during low flows.

In the flow regulator, the liquid flows into the device through the tangential inlet, imposing the vortical motion, which is sustained until the liquid reaches the outlet (Fig. 1). An air core is formed in the centre, obstructing the effective cross-section of the outlet. Discharged liquid leaves the device in the form of hollow spray cone. 


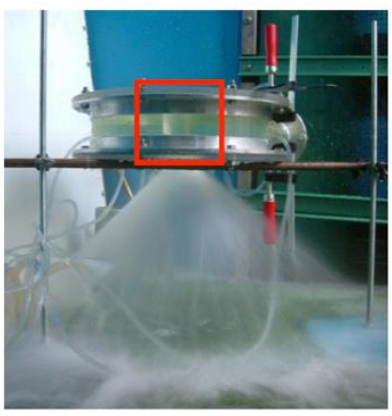

TYPE I

Single (bottom) outlet active

a)

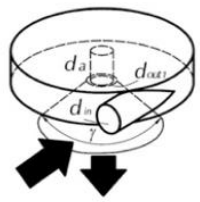

b)

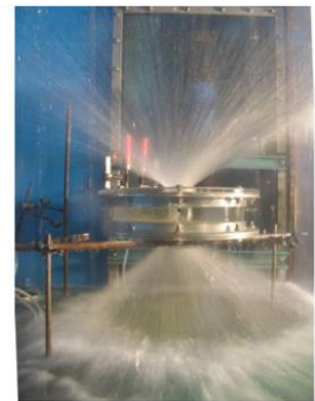

TYPE II

Two (top and bottom) outlets active

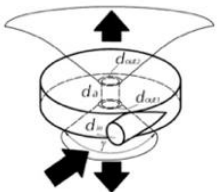

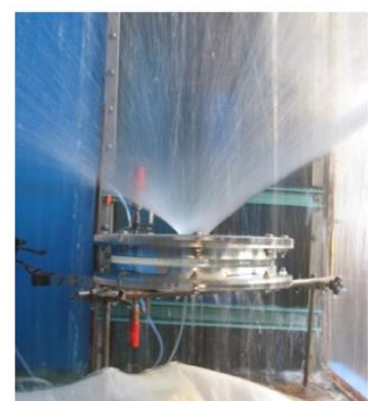

TYPE III Single (top) outlet active

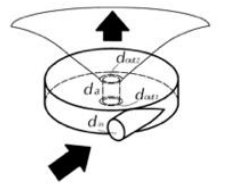

Fig. 1. Overview of three types of cylindrical vortex regulators tested (aircore is indicated by red square).

When the flow rate is low enough, the resistance is minimal and liquid flows freely, resembling "elbow flow". But when the pressure at the inlet increases, the induced vortex motion becomes stronger, intensifying the throttling effect. An interesting fact is that the flow field inside the vortex chamber is like a tornado (Rankine vortex [2]).

The aeration theory applied for vortex flow regulators is based on Henry's law, in particular the oxygen transfer in water or sewage is regulated by the molecular diffusion theory, governed by Fick's law. This general law predicts that the mass transfer rate, in the steady state, is proportional to the gas concentration gradient across the gas-liquid interface [11]. By applying this law to a water-oxygen system together with the film theory, it is possible to obtain the interphase mass transfer rate equation. This relationship allows to extract the values of the oxygen transfer coefficient based on the experimental data.

The absorption tests were performed in compliance with the unsteady state clean water test procedure [12-14] in a recirculating system. The aeration efficiency was measured by means of the overall oxygen transfer coefficient $\left(\mathrm{k}_{\mathrm{L}} \mathrm{a}_{20}, \mathrm{~h}^{-1}\right)$ adjusted to the standard conditions $\left(20^{\circ} \mathrm{C}, 101.325 \mathrm{kPa}\right)$, standard oxygen transfer rate $\left(\mathrm{SOTR}, \mathrm{kgO}_{2} / \mathrm{h}\right)$ and standard aeration efficiency $\left(\mathrm{SAE}, \mathrm{kgO}_{2} / \mathrm{kWh}\right)$.

Tap water in the system was deoxygenated with the use of sodium sulphite catalysed by cobalt chloride. The dissolved oxygen concentration in the system was monitored with Hach LDO probes at several upstream and downstream locations. The total dissolved solids concentration was monitored by a WTW TetraCon 325 electrical conductivity probe. Barometric pressure as well as water and ambient air temperature were constantly recorded during the experiments. A detailed description of experimental and chemical methods used in this study is included in our recent paper [10]. 


\section{Results}

Each vortex flow regulator type was rigorously tested for several different flow regimes to qualitatively and quantitatively describe its aeration and hydraulic efficiency.

\subsection{Flow rate vs. oxygen transfer coefficient and SOTR}

We found that the oxygen transfer coefficient $\left(\mathrm{k}_{\mathrm{L}} \mathrm{a}_{20}\right)$ and the oxygen transfer rate (SOTR) are in direct proportion to the flow rate and that all regulators types follow the same trend (cf Fig. 2 for CVR-2 type).

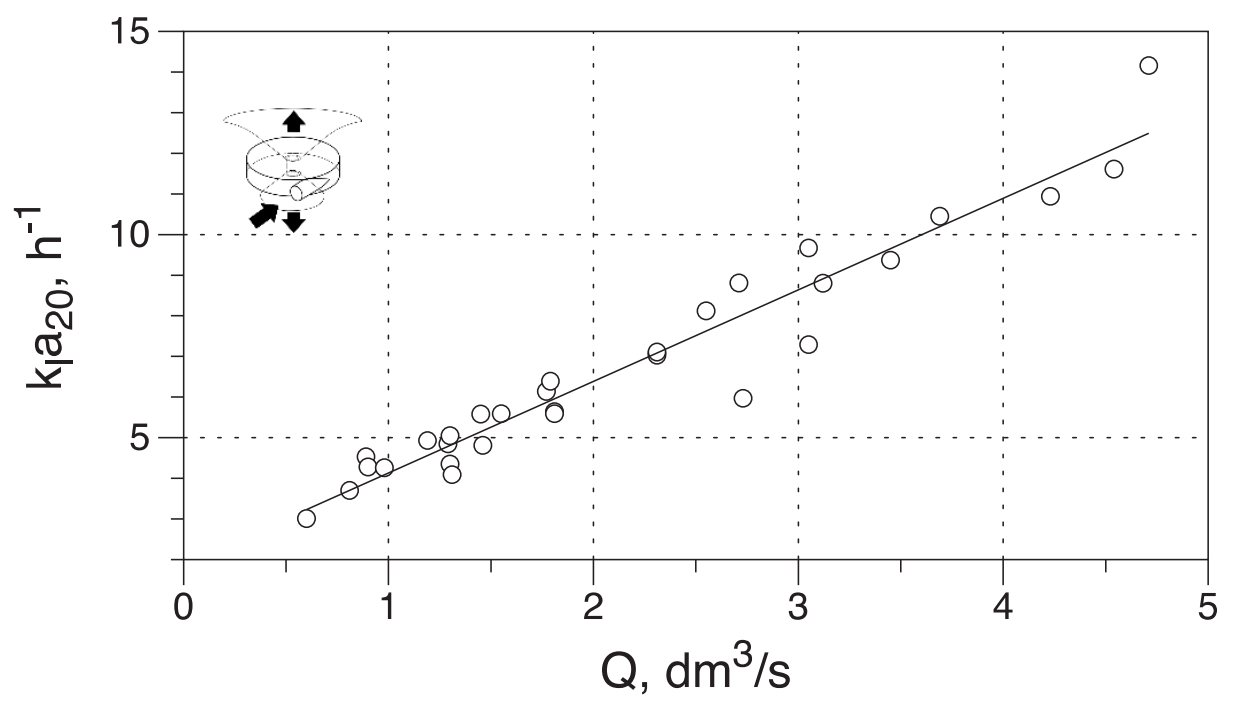

Fig. 2. Flow rate vs oxygen transfer coefficient for CVR-2 type of vortex regulator.

This result can be explained by increased turbulence and renewal rate of the liquid film available for absorption with an increasing flow rate [11]. Oxygen absorption in vortex regulators depends on several competing phenomena and the result is always a superposition of these governing parameters.

\subsection{Pressure head vs. standard aeration efficiency}

We found that the pressure head before the regulator describes the relationship with standard aeration efficiency (SAE) better than the flow rate. This parameter was decreasing with increasing pressure - approaching a limiting value above approximately 2 meters of the head (Fig. 3). The relationship between these two parameters is described with an exponential function, contrary to correlation between $\mathrm{k}_{\mathrm{L}} \mathrm{a}_{20}$ and SOTR. 


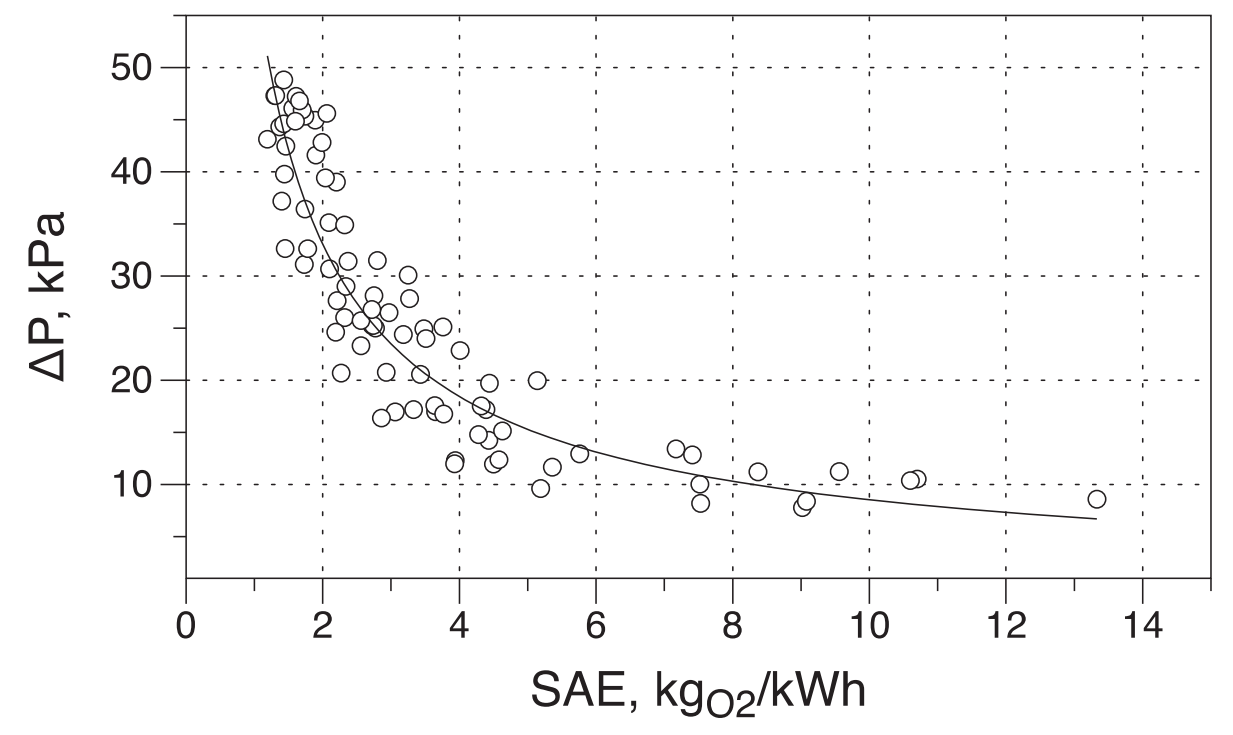

Fig. 3. Standard aeration efficiency vs. pressure head for all cylindrical vortex regulators tested.

\subsection{Effect of active outlets: one bottom (CVR) vs. two active outlets (CVR-2)}

In the type CVR-2 we were expecting to double the aeration efficiency by adding a second outlet. Indeed, the experiments proved that there was an increase, but not proportional to the number of active outlets. The oxygen transfer coefficient and the standard oxygen transfer rate were improved up to $20 \%$. Slightly better results were obtained for standard aeration efficiency. The addition of the second outlet divided the outflow between the top and the bottom one - this reduced the effective flow per area and the quality of atomisation. Also, the splashing and formation of air bubbles in the downstream basin were decreased. On the other hand, the second spray cone was formed and the contact time was longer. Of course, this effect was limited by the local saturation of droplets as the turbulence and consequently the renewal rate of the liquid film contacting with air was relatively low. We think that the major effect that limited the expected gain in aeration efficiency, was the quality of atomisation.

\subsection{Effect of active outlets: one top (CVR-U) vs. two active outlets (CVR-2)}

We observe similar competing effects for modified regulators operating with two outlets (CVR-2) and one top outlet (CVR-U). Our experiments indicated that devices operating only with the top outlet had a slightly better aeration efficiency comparing to two active outlets. 


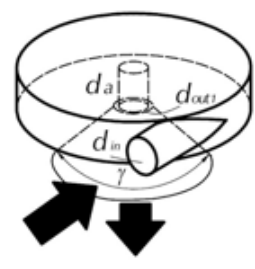

TYPE I

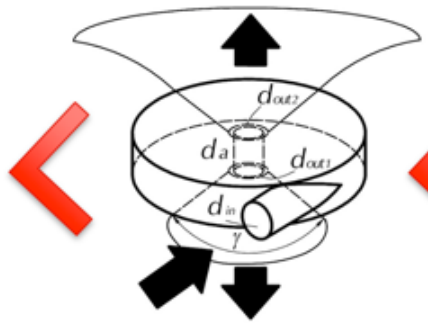

TYPE II

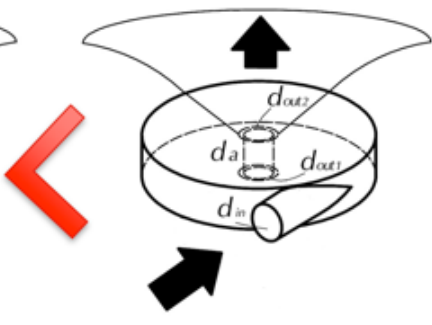

TYPE III

\section{increasing aeration efficiency}

Fig. 4. Comparison of VFR aeration efficiency.

This may prove an argument that the quality of atomisation had a major effect on the aeration efficiency of vortex regulators [15]. In this case, the increase of specific interfacial area in the second active outlet was compensated by the better atomisation and longer contact time for the regulator operating only with the top outlet.

\subsection{Effect of active outlets: one bottom (CVR) vs one top outlet (CVR-U)}

Comparing two modes of operation with outlets located on the opposite sides (CVR vs. CVR-U) - the oxygen transfer coefficient and standard oxygen transfer rate were improved up to $20 \%$ in favour of the regulators discharged with the top outlet (CVR-U). The hydraulics was similar but with the CVR-U type of regulators, the fountain-like discharge combined with inevitable gravity improved the disintegration of the liquid film and increased the contact time of droplets. On the other hand, splashing and air entrainment in the downstream basin were reduced, but the effect was not substantial.

Figure 4 summarises and compares all three types of regulators tested according to aeration efficiency.

\section{Conclusions}

The oxygen absorption in vortex regulators depends on several competing phenomena - the end result is always a superposition of these effects. We found that the best aeration efficiency can be obtained for a regulator discharged through the top outlet only (CVR-U). In general, the aeration capability of basic devices (CVR) can be increased up to $20 \%$ with a negligible effect on throttling performance. The aeration efficiency can be increased even further by combining two chambers and adding more active outlets. The aeration performance is constant and on a par with mechanical aerators and diffuser systems. Future work will concentrate on testing modified vortex regulators (CVR-2 and CVR-U) in full-scale application.

The major part of this research was made possible by a grant from the Polish Ministry of Science and Higher Education N N523 450036. 


\section{References}

1. P. Wójtowicz, A. Kotowski, J. Hydraul. Res. 47, 5 (2009)

2. A.K. Gupta, D.G. Lilley, N. Syred, Swirl flows (Abacus Press, Tunbridge Wells, Kent, 1984)

3. R.R. Long, J. Meteorol. 15, 1 (1958)

4. M. Escudier, Annu. Rev. Fluid Mech. 19, (1987)

5. H.A. Einstein, La Houille Blanche 10, 4 (1955)

6. P. Wójtowicz, M. Szlachta, Water Sci. Technol. 67, 12 (2013)

7. A.H. Nielsen, J. Vollertsen, H.S. Jensen, T. Wium-Andersen, T. Hvitued-Jacobsen, Water Res. 42, 15 (2008)

8. N.A. Jensen, Water Environ. Res. 67, 6 (1995)

9. J.L. Huisman, N. Weber, W. Gujer, Water Res. 38, 5 (2004)

10. P. Wójtowicz, M. Szlachta, Chem. Eng. J. 287, (2016)

11. W.K. Lewis, W.G. Whitman, Ind. Eng. Chem. 16, 12 (1924)

12. ASCE, Measurement of oxygen transfer in clean water, American Society of Civil Engineers, ANSI/ASCE 2-91, Reston, Va. (2007)

13. DWA, Measurement of the Oxygen Transfer in Activated Sludge Aeration Tanks with Clean Water and in Mixed Liquor, German Association for the Water Environment, (1996)

14. CEN, Wastewater treatment plants W Part 15: Measurement of the oxygen transfer in clean water in aeration tanks of activated sludge plants (EN 12255:15), European Comittee for Standarization, (2003)

15. A. Lefebvre, Atomization and sprays (Taylor\&Francis, New York, 1989) 